war from 1878-1880 and was present at the action on the Helmund, the battle at Maiwand, and the defence of Kandahar (mentioned in despatches, medal and clasp). He served in the Burmese expedition, 1886-7 (mentioned in despatches, medal and clasp, and the Distinguished Service Order).

\section{Journal of THE ROYal ARMY Medical CoRPs.}

The Journal of the Royal Army Medical Corps, apart from the more strictly scientific subjects, frequently makes its pages interesting by giving short biographies of past service worthies. The February issue contains an account of the life of Robert Jackson, Inspector-Greneral of Hospitals, who was born at Stone Byers near the Falls of clyde in 1750 . "Many army medical officers," says Major H. A. L. Howell, the author of the article, "have attained greater honours, but few men have done more to improve the condition of the British soldier and the army surgeon." Other articles are an important Report on the Determination of the Amount of Tin in Tinplate used for Canning Preserved Food, by Major W. O. Beveridge, D.S.O. ; a Note upon Yellow Fever, Bilious Remittent and Remittent Fevers in West Africa, by Sir Rubert Boyce, F.R S.; and Blood-Culture in Typhoid Fever, by Major S. L. Cummins.

Measles at the Royal Naval College, Dartmouth.

The Iimes states that over 60 cases of German measles and other minor ailments among the naval cadets at the Royal Naval College, Dartmouth, are under treatment. The Prince of Wales and Prince Albert are in good health.

Surgeon-Lieutenant-Colonel C. R. Kilkelly, C.M.G., M.V.O., has tendered his resignation as house governor and medical superintendent of the Osborne House Convalescent Home for Army and Navy Officers.

\section{Cortespondence.}

\section{"Audi alteram partem." \\ GIRLS' SCHOOLS, GAMES, AND NEURAS- THENIA.}

To the Editor of THE LANCET

SIR,-Having read with much interest and agreement $\mathrm{Dr}$. Robert Jones's letter on Girls' Schools, Games, and Neurasthenia, in The LANCET of Feb. 4th, I am impelled to write and endorse heartily most of what he says.

Having had 12 years' experience of nervous work amongst women and girls, I feel strongly also that the practically continuous time table at a large number of the best schools for girls is responsible for much of the restless incapacity to interest and occupy themselves satisfactorily which manifests itself later when these same girls return to their homes. To it, too, is due the fact that valuable and characterbuilding knowledge is so ill assimilated that it fails to make life a comprehensible and interesting whole to the girl, who should feel it only too short in which to compass the many activities which make their appeal to the efficiently educated individual.

The failure to make life, practically anywhere in the world, interesting, is the worst accusation that can be brought against any system of education-and it can with justice be brought against much of the education of girls to-day. The reason appears to me to be that urged by Dr. Jones-i.e., that with a continuous round of lessons and games, the knowledge absorbed from both has no time in which to be digested. The girls have no time in which to see how knowledge applies to life. It is this assimilation which makes the competent, self-reliant woman, who will be able to enjoy applying what she has learnt to whatever circumstances she may find herself in-who will be able to regard games in their proper proportion, and not become hipped and morbid because there is no hockey team in her neighbourhood, wandering aimlessly through life, like one I know of, who said she had sold her bicycle because she found it took so much shorter a time to bicycle than to walk, and she did not know what to do with her dass.

This demand for more free time for development of individuality and character is not met by the argument that the girls will only use the time given them badly. If this be so, what then is likely to occur when they have the management of far more of their time on leaving? Time is like money and can only be understood in the use of it. What Dr. Jones says as to the mental effect of the separation of exercise from work is exceedingly true. While having no quarrel with games, which are excellent in their place, there is a feeling of satisfaction in getting exercise from doing practical work which has no counterpart in games. I know of one school where the pupils laid out most of the grounds with excellent results. This was an attempt "to establish a proper coördination of the different branches of knowledge material."

In what Dr. Jones calls " the wild cult of athleticism" by girls, or rather by their teachers for them, as a means to health, it is sometimes forgotten that sound health is the power of ready adaptation to as widely different conditions as possible, and tirat it is as truly a test of health to be able to sit up for several nights in succession, and to stay for a week in the house if necessary, as it is to be able to walk 15 miles or play a hard game of hockey without showing signs of deterioration, mental, moral, or physical, under any of these stresses. One thing is sure, that the physique, well cultivated and adapted to games, does not alone protect from nervous breakdown, and if the girl be incidentally led to think of her own physical or mental development as the important matter apart from its use, it may even "carve the way for the worst ty pe of nerves "-characterised by egoism, introspection, hypochondriasis, and consequent depression.

"This is the true joy of life, the being used for a purpose recognised by yourself as a mighty one ; the being thoroughly worn ont before you are thrown on the scrap heap; the being a force of nature, instead of a feverish, selfish clod of ailments and grievances, complaining that the world will not devote itself to making you happy." (George Bernard Shaw.) I am, Sir, yours faithfully, Hove, Feb. 6th, 1911.

A. Helen A. Borlie.

\section{THE NEW BUILDING OF THE ROYAL SOCIETY OF MEDICINE. \\ To the Editor of THE LANCET.}

SiR,--The praiseworthy effort to erect a building worthy of the Royal Society of Medicine, and especially for the housing of the magnificent library, deserves encouragement in every way. It must, however, be borne in mind that to Fellows resident in distant parts of the world very little benefit accrues beyond the receipt of the Proceedings. For us the departure in library practice (initiated by the Secretary, Mr. MacAlister), in being able to get abstracts made on any subject of interest to the worker, is invaluable. It does not demand a great tax on the imagination to appreciate the position of absolute deadlock for want of references.

I am convinced that if this procedure were more widely known it would induce a number of workers to join the society who up to the present have stood aloof, as the benefits corresponding to a three-guinea subscription were not apparent. It must necessarily involve some expenditure, but it appears to be an investment in the right direction and aims at carrying out the true object of the society.

I wish to extend $m y$ personal thanks to the council of the Royal Society of Medicine for the departure, and to express the hope that it will be continued and encouraged, and published more widely.

I am, Sir, yours faithfully,

Johannesburg, Jan. 16th, 1911. G. A. E. MURRAY.

\section{SEASONAL COLOUR CHANGES.}

To the Eaitor of THE LANCET.

SIR,-I am endeavouring to collect all the facts I can bearing upon the change which takes place by the animal which is the brown stoat in summer and the white ermine in winter. Some important questions of physiology are involved in its explanation. Does the change occur as a matter of season independently of temperature, or is it connected with actual cold? At what precise period of the year does it usually begin? When an animal has been in winter piumage - more correctly veltage - at what date and under what conditions does it again become brown? We have recently obtained at the Haslemere Museum a beautiful ermine of this 